\title{
Fault/no fault: bearing the brunt of medical mishaps
}

\begin{abstract}
"I'd rather not talk about it, even though in the end no fault was found. For 7 years it went on, months sitting in court listening to what a terrible person you are, no one recovers from that. It is on your mind every day, every minute. It changed the whole way I practised. The empathy I had, that I was known for, just wasn't there any more. Every patient was a potential lawsuit." - retired Canadian doctor
\end{abstract}

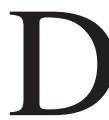

octors don't want to talk about it. When $C M A J$ spoke over the telephone with the doctor quoted above, who didn't want his name used, hurt and anger seeped into his voice as he described the events that occurred over 25 years ago.

His experience was not unusual.

The Stress of Medico-Legal Difficulties is a publication from the Canadian Medical Protective Association, which provides medical liability protection to about $95 \%$ of Canadian doctors. In it, an unnamed doctor describes his response to a lawsuit: "I had tachycardia. I suffocated. I couldn't sleep and was ashamed to show my face at work." That doctor reported that support from patients and colleagues alleviated much of his stress, and suggests remembering that "we're all in this together."

But the physician CMAJ spoke with had a starkly different experience:
"Except for one or 2 friends, I felt abandoned by my peers. It was as if they thought what was happening to me might contaminate them."

Is there a better way to deal with the issue of compensation for patients injured by medical mishap?

Around the world, developed nations are struggling to find ways to streamline the process of compensating patients who have suffered injury as a result of what is variously called adverse or avoidable events, misadventures, medical error or fault.

Under Canada's tort-based system (Box 1), patients have no automatic avenue for obtaining redress. Even filing a complaint is often problematic and difficult (CMAJ 2008;178[1]:14-6). In the United States, the complaints system is slightly more user friendly, while malpractice awards, although infrequent, are typically enormous (CMAJ 2008; 178[6]:671-3). European processes vary widely, with some jurisdictions coupling compensation schemes with the regulation of physicians and complaints (CMAJ 2008;178[11]:1409-11).

Streamlining the process of compensation has taken different forms around the world.

In some countries, the escalating cost of medical liability insurance to defend against lawsuits has been the impetus for reforms, which often focus on legal and administrative change. In

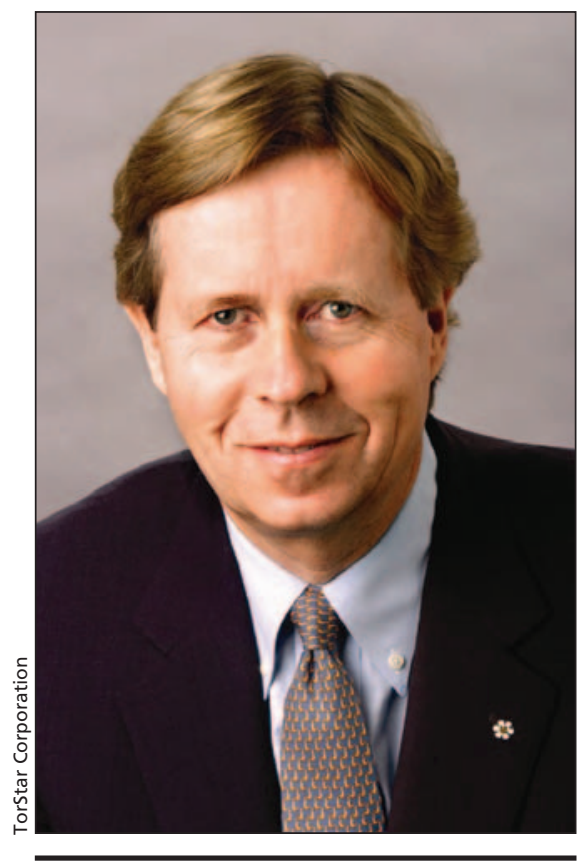

The failure to implement no-fault compensation in Canada means that "victims continue to bear the brunt of the accidents and their often devastating consequences," says Robert Prichard, who wrote the landmark report Liability and Compensation in Health Care (1990).

other countries, the need to prove fault before compensation is awarded has been the stumbling block.

The Danish Medical Association, for example, supported a move to no fault in 1992 because it felt that a significant proportion of lawsuits brought against doctors were launched solely for the purpose of obtaining compensation (Box 2).

"Patients could only get compensation if they could prove negligence, but we said a lot of things happen with no liability. For example, sometimes people have wound infections after surgery and you couldn't blame the individual doctor," says former association president Jesper Poulson. "Now patients can be compensated for suffering if the outcome is worse than could reasonably be expected."

Compensation pay outs are, however, in "much smaller amounts" than might be expected from successful lawsuits in 
countries like Canada and the United States, Poulson adds.

New Zealand introduced a no fault accident insurance scheme in 1974 after a major report concluded that a tort, or fault-based liability system was too erratic for accident victims (including patients) who needed a secure source of support. Oddly, though, compensation fault until 2005, when the law was amended to introduce the category "treatment injury," allowing for payments regardless of perceived fault. The new scheme was backed by the New Zealand Medical Association: "It provides a much more equitable outcome for patients" and helps to avoid adversarial situations, stated association President Dr. Peter Foley (JMAJ 2008;5:58-60).

For its part, the United Kingdom, which has a tort-based liability system like Canada's, passed the Redress Act in 2006 in a bid to make it easier for patients who suffer harm to have their situation investigated, and to receive an explanation, apology and compensation without the need to go to court. The scheme covers claims up to $£ 20000$ (Cnd\$40 060), but patient groups have been critical of it and the jury is out on its effectiveness.

Here in Canada, no-fault compensafor patients involved determination of

tion was the subject of a landmark 1990 report, Liability and Compensation in Health Care, crafted by former University of Toronto president Robert Prichard.

Commissioned by the Conference of Deputy Ministers of Health, the exhaustive Prichard Report, which includes 4 hefty volumes of appendices, noted that more than $50 \%$ of all money spent on malpractice goes to the expenses of litigation and not to the injured patient for compensation.

It recommended major changes, arguably the most important of which is that patients would still have recourse to the courts, but would have the choice of opting for a no-fault compensation scheme. This innovation, Prichard argued, would limit the growth of lawsuits while ensuring that proportionately more who suffered injury would receive compensation.

The report's recommendations were largely based on the premise that the increasing numbers of lawsuits and size of settlements meant the tort-based system was heading for an affordability crisis. That crisis, however, failed to materialize, as Canada did not experience the "claims expansion" that typified other countries with similar medical malpractice regimes, despite the fact that class

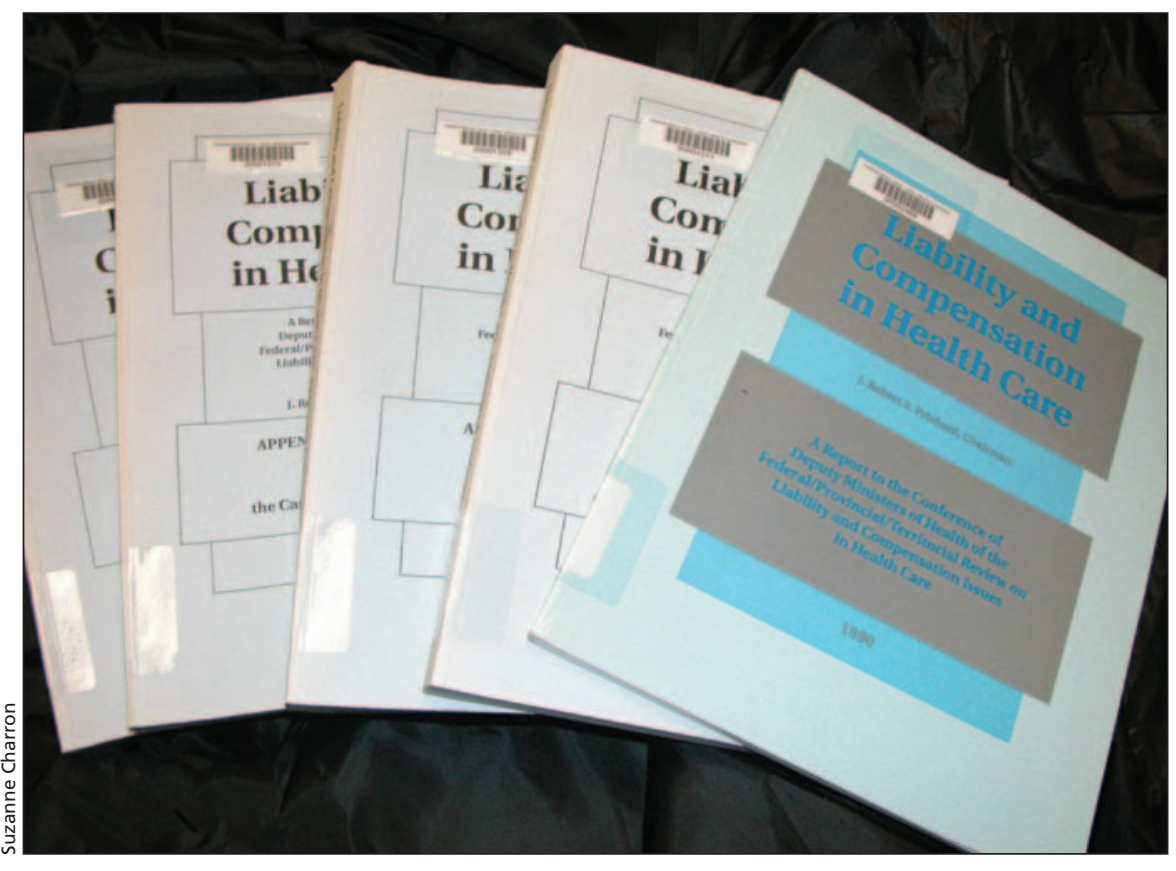

The Liability and Compensation in Health Care study found that $50 \%$ of monies spent on malpractice goes to cover the cost of litigation and not to the injured patient. action suits were subsequently permitted in several provinces. Part of the reason that costs were kept down was a 1978 Supreme Court of Canada decision that put a cap on non-economic damages.

Prichard's report, in turn, disappeared onto library shelves, as has the Health Council of Canada's 2006 annual report, which recommended that a no fault system be re-examined so that health care providers "are more open to disclosing errors and injured patients can be compensated without having to sue the provider." Similarly, a pair of reports in 2006 commissioned by Health Canada's now-defunct Health Policy Research Program, which looked at the no fault experience around the world and its potential application to Canada, are now discussed only at conferences.

Prichard, now president of Torstar Corporation, expresses "disappointment" at the inaction on behalf of the victims of medical malpractice.

Hospitals and doctors "are taking more care and are better at understanding systemic injuries, which is positive," says Prichard, who was dean of law at the University of Toronto when the report was written. "But the victims continue to bear the brunt of the accidents and their often devastating consequences. And these victims have no representative in the legislatures." As for the burden placed on doctors, the report found that the "most significant negative effects of civil liability claims on physicians have been the development of symptoms of stress, anxiety and anger and the resulting diminution of their satisfaction with the practice of medicine."

In short, the issue of no-fault compensation is all but invisible in Canada, in terms of public profile, in part because patients, as Prichard suggested, are not an organized lobby group. As well, most lawsuits are settled out of court and silence is usually a condition of settlement reached between patients and insurers, which include the Canadian Medical Protective Association and the Healthcare Insurance Reciprocal of Canada. In 1988, the Canadian Medical Association recommended (in a brief to Prichard's review) that the federal government study the benefits and costs of an alternative accident compensation 


\section{Box 2: No-fault compensatory regimes}

Claims falling within a predefined class of avoidable adverse events are automatically paid by a public fund or through private resources without a formal finding of negligence through the court process.

\section{Advantages}

- prompt redress to victims for comparatively cheaper administrative and legal costs (5\%-30\%, as compared with $40 \%-60 \%$ in the tort liability system)

- avoi dable standards" create the conditions for more open exchange about the circumstances that led to errors and hence foster the development of more efficient independent error reporting and risk mitigation systems

- award amounts are more consistent

\section{Drawbacks}

- could result in more claims per capita, which could result in higher costs if introduced anew into a jurisdiction

- level of compensation may be insufficient

- coverage usually limited to avoidable adverse events as decided by a group of expert advisors

- possible lack of personal accountability of physicians

Main challenge

Establishing a set of triggers and criteria for compensation, scope of coverage and level of damages - hence these systems typically undergo several reforms to fine tune coverage decisions.

Source: Medical Malpractice: Prevention, Insurance and Coverage Options, published by the Organisation for Economic Cooperation and Development in 2006.

and its acceptability to the Canadian public, but there has been no follow up.

Meanwhile, opinions about the merits of the current system are divided. In the latest Canadian Medical Protective Association annual report, President Dr. Peter Fraser wrote that members "sleep better at night" because the association exists. And in a 2006 Organisation for Economic Co-operation and Development report on medical malpractice, Canada's system compared favorably to those in other countries.

Winnipeg-based Dr. Rob Robson, who spent 10 years as a claims manager for the protective association, believes strongly that doctors have a right to a legal defence and has no problems with the association's activities. But he left his association job to train as a mediator at Harvard University because he learned that "when you use a confrontational system like tort law, you keep people apart. At the end of the process the doctors are mad, patients are mad and the system doesn't change."

Toronto lawyer Douglas Elliott, who has done "a reasonable amount" of medical malpractice litigation on behalf of plaintiffs, says he's not a big fan of tort "but it's better than nothing." And he acknowledges it can be a deterrent. For example, for years doctors overprescribed blood transfusions to "get patients up and around quicker" — notwithstanding inherent risks - because the blood was "free". It was only fear of litigation that led to them to take a more conservative approach, Elliott says.

Elliott, however, favours the introduction of no-fault compensation, arguing that the current system is fair to doctors, but not to patients. And he decries the fact that individuals must bear the cost of litigation against doctors, whose insurance premiums are mostly paid by taxpayers via provincial health ministries (as part of fee negotiations).

The retired doctor, quoted at the beginning of this article, would have appreciated a no-fault system that could have spared him the lengthy and traumatic experience of going to court. Still, he wonders about those "difficult situations where doctors are totally wrong" and their negligence causes permanent harm to patients. But lawsuits aren't the only answer. Countries with no-fault compensation systems typically have separate processes for discipline and corrective action to prevent harm to future patients. - Ann Silversides, CMAJ

DOI:I0.I503/cmaj.081020

In the next issue of CMAJ: Experts weigh in on whether the tort-based liability system and fear of litigation spell trouble for the growing patient safety movement.

\section{Incoming CMA president}

\section{impatient for reform}

I $\mathrm{t}$ could be argued that the incoming president of the Canadian Medical Association (CMA) is a trifle impatient. After all, Dr. Robert Ouellet says that he is "allergic" to pilot projects and "a bit against consensus because I am a man of action."

The problem with consensus, the 62-year-old radiologist explains, is that it smacks of more discussion, more study, which essentially impedes the goal of improving access in Canada's health care system. "It's not the time to do studies. We have so many studies. In Quebec, we are champions at this," says the former Quebec Medical Association president. Rather, the CMA should take the plunge and make concrete proposals for change.

The second consecutive private clinic owner/operator to assume the CMA helm, Ouellet will succeed Dr. Brian Day on Aug. 20, 2008, at the association's annual general meeting in Montréal, Quebec.

Ouellet opened Canada's first private computed tomography (CT) scan clinic and now owns a stake in 4 other clinics in Quebec, including a pair of magnetic resonance imaging (MRI) clinics that his radiation technologist wife, Diane Marceau, oversees.

Ouelett wants to inject more competition into the system and foster more public-private partnerships. "Nobody

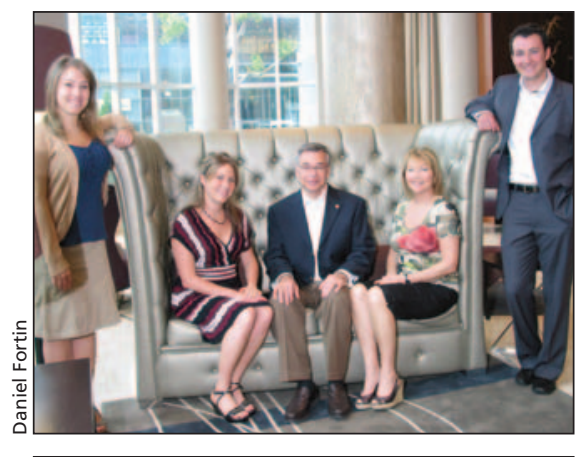

Radiologist Dr. Robert Ouellet, pictured here with his family, will become the second consecutive private clinic owner/operator to head the Canadian Medical Association. From left to right: daughters, Sandra and Julie, spouse, Diane, and son, Maxime. 